\title{
Revised description of Simulium (Nevermannia) sasai, a rare and poorly known species in Japan (Diptera: Simuliidae)
}

\author{
Hiroko SATo ${ }^{1)}$, Katsumi Saito ${ }^{2)}$ and Hiroyuki TAKaOKA ${ }^{1)}$ \\ 1) Department of Infectious Disease Control, Faculty of Medicine, \\ Oita University, Hasama, Yufu City, Oita, 879-5593 Japan \\ ${ }^{2}$ Laboratory of Medical Zoology, College of Environmental Health, Azabu University, \\ 1-17-71, Fuchinobe, Sagamihara, Kanagawa, 229-8501 Japan
}

(Received: 26 July 2005; Accepted: 14 September 2005)

\begin{abstract}
Simulium (Nevermannia) sasai (Rubtsov), a rare and poorly known black-fly species in Japan, is taxonomically revised: its female, male and pupa are fully described, and the mature larva is described for the first time on the basis of samples collected in Kanagawa Prefecture, Honshu, Japan. The morphological characters of $S$. (N.) sasai are compared to those of its related species within the feuerborni speciesgroup to which this species is assigned.
\end{abstract}

Key words: Simulium, black fly, Simuliidae, Japan, description, Nevermannia

Simulium (Nevermannia) sasai (Rubtsov), is a rare species among the 66 known black-fly species in Japan (Crosskey and Howard, 1997) although it has wide geographical distribution from Tochigi in Honshu southward to Kagoshima in Kyushu (Bentinck, 1955; Takaoka et al., 1977). At present, this species has been classified in the feuerborni species-group within the subgenus Simulium (Nevermannia) Enderlein since a world list of Simuliidae was published by Crosskey and Howard (1997).

Simulium (N.) sasai has been relatively poorly known. So far only its female and male adults and pupa have been illustrated under Simulium sp. J-14 (Bentinck, 1955), and its larva has remained undiscovered. No full descriptions of all stages of this species are available.

We here give descriptions of the female, male (both sexes reared from pupae), pupa, and mature larva based upon samples collected in Kanagawa Prefecture.

The terms for morphological features used here follow those of Takaoka (2003).

\section{Simulium (Nevermannia) sasai (Rubtsov)}

Eusimulium sasai Rubtsov, 1962: 310-312 (illustratations of female, male and pupa, all from Bentinck, 1955); Orii, Uemoto and Onishi, 1969: 2.

Simulium (Nevermannia) sasai: Crosskey and Howard, 1997: 46.

Simulium (Eusimulium) sasai: Ogata and Uemoto, 1971: 61; Uemoto, 1985: 329.

Simulium sp. J-14 Bentinck, 1955: 1-23

(illustrations of female, male and pupa).

DESCRIPTION. Female. Body length about $3.2 \mathrm{~mm}$. Head. Narrower than thorax. Frons brownish-black, slightly shiny at certain angle of light, thinly whitish-grey pruinose, densely covered with whitish-yellow recumbent hairs interspersed with several dark brown longer and stouter hairs along each lateral margin. Frontal ratio $1.7: 1.0: 2.5$. Frons-head ratio 1.0:4.7. Fronto-ocular area (Fig. 1A) well developed, triangular, directed somewhat upward. Clypeus brownish-black, whitish-grey pruinose, densely covered with whitish-yellow recumbent hairs (except portion near upper margin bare) intermixed with several dark longer and stouter hairs on each side. Labrum 


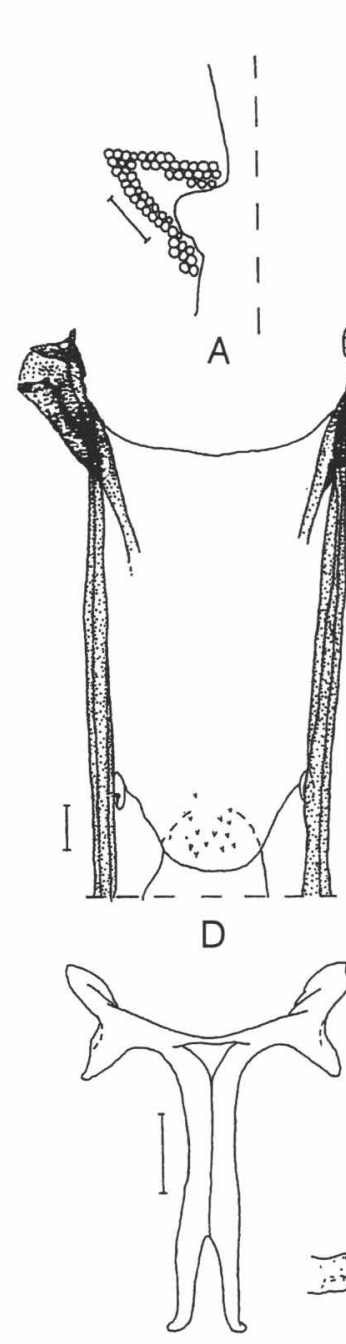

$\mathrm{E}$

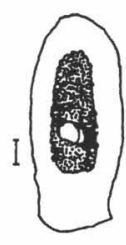

C
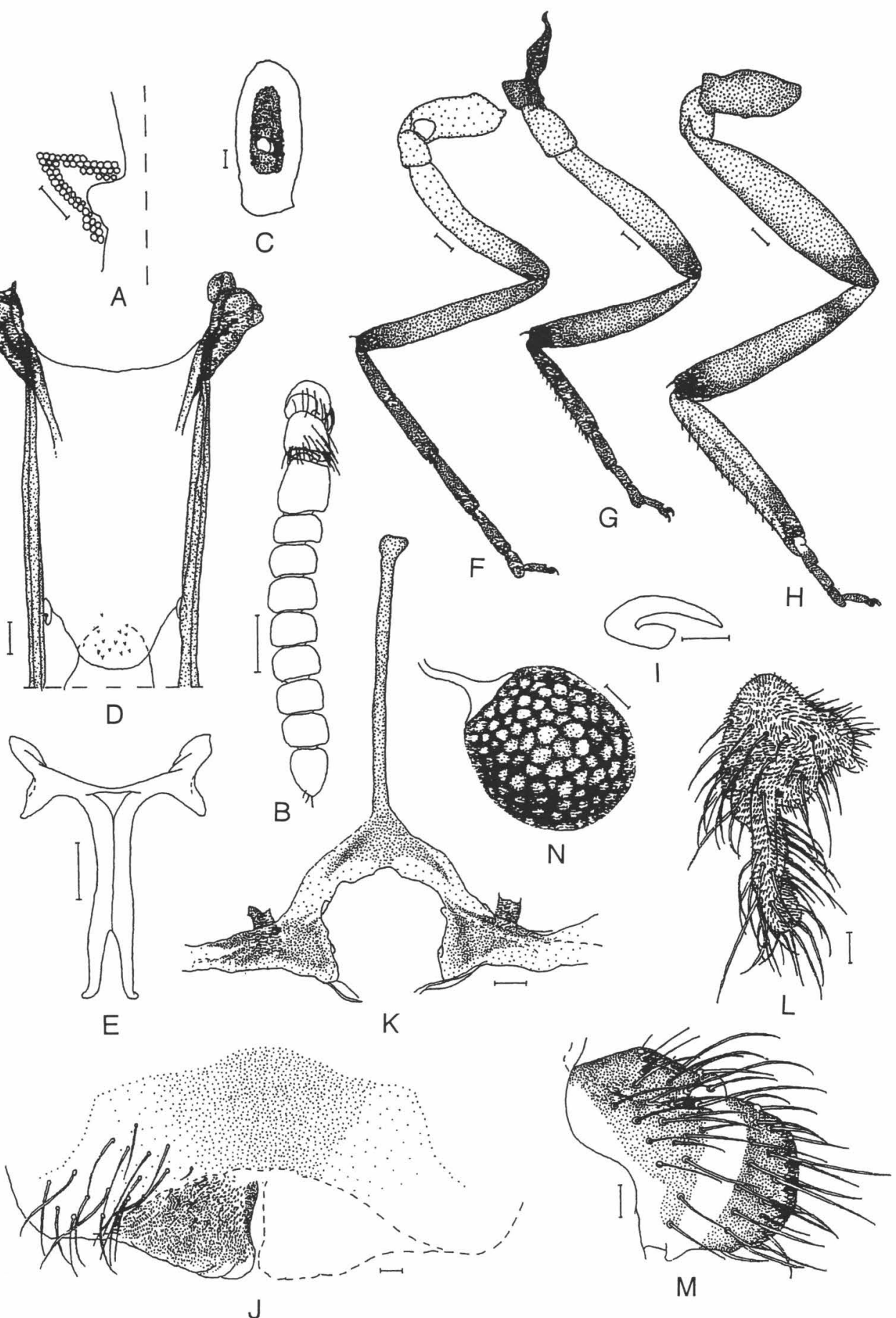

Fig. 1. Female of Simulium (Nevermannia) sasai. A, fronto-ocular area (right side); B, antenna; C, 3rd segment of maxillary palp with sensory vesicle (right side, front view); D, cibarium; E, furcasternum; F, foreleg; G, midleg; H, hind leg (left side, outer view); I, claw; J, 8th sternite and ovipositor valves in situ (ventral view); K, genital fork (ventral view); L and M, paraprocts and cerci (right side; L, ventral view; $\mathrm{M}$, outer view); N, spermatheca. Scale bars. $0.1 \mathrm{~mm}$ for A, B and E-H; $0.02 \mathrm{~mm}$ for C, D and I-N. 
about 1.1 times as long as clypeus. Antenna (Fig. 1B) composed of $2+9$ segments, brownish-black, except scape, pedicel, and basal $1 / 2$ of 1st flagellar segment yellow; 1st flagellar segment elongate, 1.9-2.2 times as long as 2nd one. Maxillary palp consisting of 5 segments, blackish, proportional lengths of 3rd, 4th, and 5 th segments $1.0: 0.8-1.2: 1.9-2.1 ;$ 3rd segment (Fig. 1C) much enlarged, with sensory vesicle elongate, about 0.6 times as long as 3rd segment, with medium-sized opening. Maxillary lacinia with 9 inner and 12 outer teeth. Mandible with 22 inner teeth and lacking outer teeth. Cibarium (Fig. 1D) smooth on posterodorsal margin, with well sclerotized arms directed anterolaterally, and with some spines on membranous area near ventral margin. Thorax. Scutum brownish-black, whitish-grey pruinose (in alcohol, scutum dark brown with central portion and anterolateral calli light brown, with no dark longitudinal median and submedian vittae), densely covered with whitish-yellow recumbent hairs, and with several dark brown upright hairs on prescutellar area. Scutellum medium brown, with several dark brown upright hairs as well as whitishyellow shorter hairs. Postnotum dark brown, whitish-grey pruinose, and bare. Lateral surface of thorax dark brown to brownish-black, whitish-grey pruinose, and bare. Pleural membrane bare. Katepisternum longer than deep, dark brown, and bare. Furcasternum (Fig. 1E) with a distinct apodeme directed downwards on each arm. Legs. Foreleg (Fig. 1F): coxa and trochanter whitish-yellow; femur whitishyellow basally, gradually darkened towards apex, and with apical cap medium brown (in alcohol, femur dark yellow with apical cap medium brown); tibia dark brown with apical cap black; tarsus black; basitarsus slender, slightly dilated, 8.2 times as long as its greatest width. Midleg (Fig. 1G): coxa brownish-black; trochanter yellow; femur yellow, with apical cap dark brown; tibia light brown basally, gradually darkened towards apex, and with apical cap black (in alcohol, tibia dark yellow to light brown except apical cap and posterior surface brownish-black); tarsus black. Hind leg (Fig. 1H): coxa medium brown; trochanter yellow; femur dark yellow with apical cap dark brown; tibia dark brown to black with base yellow, and outer portion light brown medially; tarsus dark brown to black with median large portion of basitarsus dark yellow, and basal
$1 / 2$ of 2 nd segment whitish; basitarsus nearly parallel-sided, 5.7 times as long as wide; calcipala well developed, nearly as long as wide; pedisulcus well developed. Claws (Fig. 1I) each with large basal tooth 0.45 times as long as claw. Wing. Length $3.2 \mathrm{~mm}$. Costa with 2 parallel rows of dark short spines as well as dark hairs except subbasal portion of costa near humeral cross vein with patch of whitish hairs. Subcosta with dark hairs except near apex bare. Basal portion of radius fully haired; $R_{1}$ with dark spinules and hairs; $R_{2}$ with dark hairs. Hair tuft on stem vein dark brown. Basal cell absent. Abdomen. Basal scale light brown, with fringe of whitish-yellow long hairs. Dorsal surface of abdomen dark brown, densely covered with whitish-yellow short hairs interspersed with dark ones; tergites 6-8 slightly shiny when illuminated; ventral surface of segment 7 with large medial sternal plate. Genitalia. Sternite 8 (Fig. 1J) wide, bare medially but furnished with about 18 short and long hairs on each side. Ovipositor valves (Fig. $1 \mathrm{~J}$ ) triangular, thin, membraneous except inner margin narrowly sclerotized, densely covered with microsetae interspersed with 8 short hairs; inner margins gently sinuous and narrowly separated medially from each other. Genital fork (Fig. 1K) of inverted Y-form, with well sclerotized stem and wide arms; each arm with wide round lobe-like projection directed medioposteriorly and prominent projection directed forward. Paraproct (Fig. 1L, M) of usual form, only slightly protruding ventrally. Cercus in lateral view (Fig. $1 \mathrm{M}$ ) rounded posteriorly, 0.69 times as long as paraproct. Spermatheca (Fig. 1N) globular, strongly sclerotized except small area around juncture to duct, and duct itself unsclerotized, with distinct reticulate surface pattern, and without internal setae; main spermathecal duct narrow, while both accessory ducts slightly wider than main duct.

Male. Body length about $3.5 \mathrm{~mm}$. Head. As wide as thorax. Holoptic; upper eye consisting of large facets in 21 vertical columns and 22 horizontal rows. Clypeus black, not shiny, whitish pruinose, moderately covered with pale and dark simple hairs. Antenna composed of $2+9$ segments, light brown to brownishblack except basal $1 / 3$ of 1 st flagellar segment yellow; 1st flagellar segment elongate, about 1.8 times as long as 2nd one. Maxillary palp dark brown, composed of 5 segments, propor- 


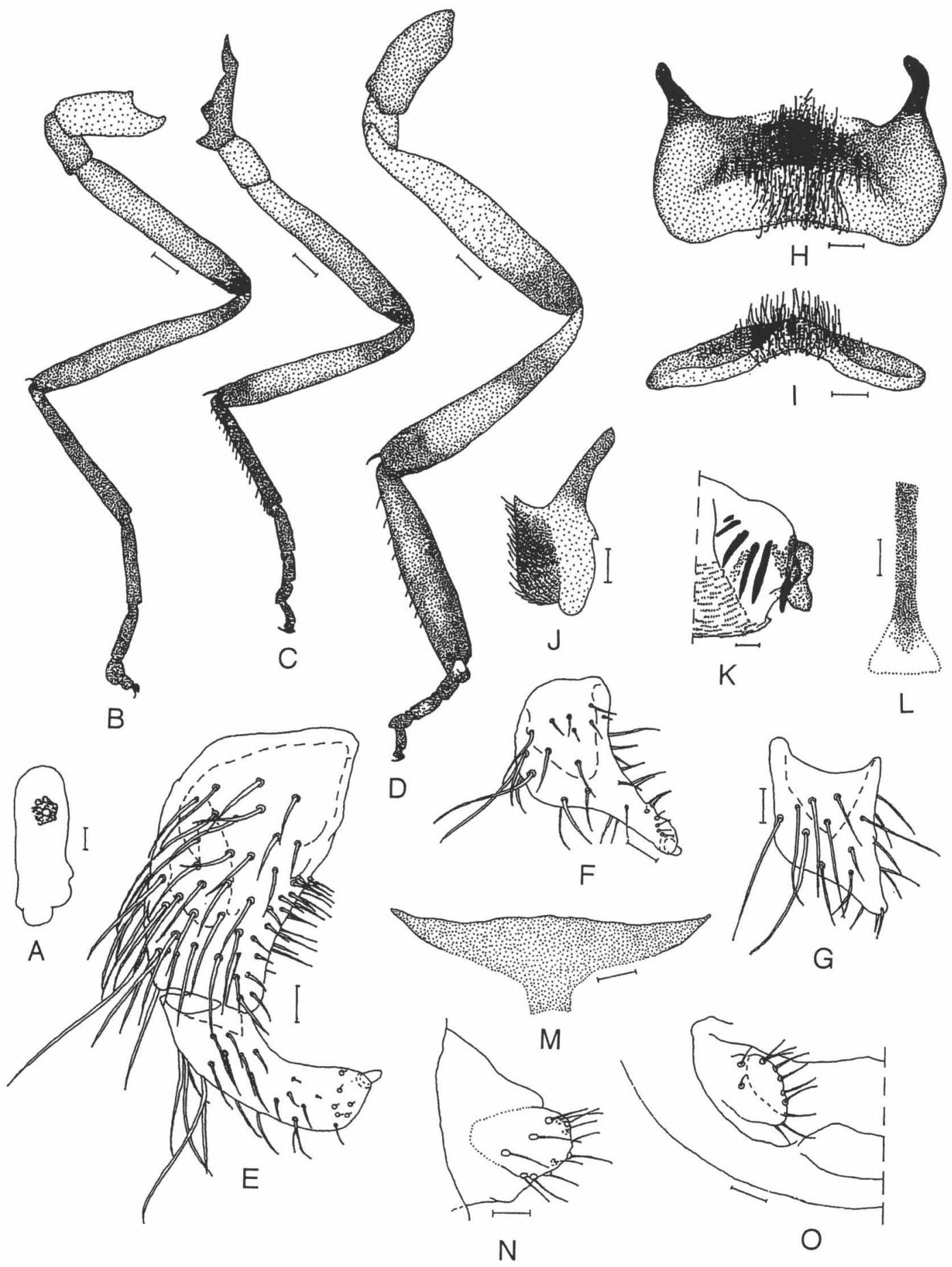

Fig. 2. Male of Simulium (Nevermannia) sasai. A, 3rd segment of maxillary palp with sensory vesicle (right side, front view); B, foreleg; C, midleg; D, hind leg (left side, outer view); E, coxite and style (right side; ventral view); F and G, styles (right side; F, end view; G, ventrolateral view); H-J, ventral plates (H, ventral view; I, end view; J, lateral view); K, paramere and aedeagal membrane (left side; end view); L, median sclerite; M, dorsal plate; $\mathrm{N}$ and $\mathrm{O}$, 10th abdominal segments with cercus (right side; N, lateral view; O, end view). Scale bars. $0.1 \mathrm{~mm}$ for $\mathrm{B}-\mathrm{D} ; 0.02 \mathrm{~mm}$ for $\mathrm{A}$ and $\mathrm{E}-\mathrm{O}$. 
tional lengths of $3 \mathrm{rd}, 4 \mathrm{th}$, and 5 th segments $1.0: 1.0: 2.3$; 3rd segment (Fig. 2A) of moderate size; sensory vesicle (Fig. 2A) small, globular or ellipsoidal, 0.18 times as long as 3rd segment. Thorax. Scutum black (in alcohol, scutum medium brown with 3 faint dark longitudinal vittae), slightly shiny at certain angle of light, densely covered with golden-yellow recumbent hairs interspersed with several black upright hairs on prescutellar area. Scutellum brownish-black, with many black upright long hairs as well as golden-yellow shorter hairs. Postnotum brownish-black to black, whitishgrey pruinose, and bare. Lateral surface of thorax brownish-black, whitish-grey pruinose. Pleural membrane bare. Katepisternum longer than deep, dark brown, and bare. Legs. Foreleg (Fig. 2B): coxa yellow; trochanter medium brown; femur medium brown basally, gradually darkened toward apex, and nearly blackish apically; tibia brownish-black to black; tarsi entirely black; basitarsus slender, cylindrical, 9.5 times as long as its greatest width. Midleg (Fig. 2C): coxa brownish-black; trochanter yellow; femur yellow basally, darkened toward apex, with apical cap blackish (in alcoholic specimen femur appears yellowish except apical dark cap); tibia brownish-black with outer surface somewhat paler medially; tarsus black. Hind leg (Fig. 2D): coxa dark brown; trochanter yellow; femur yellow basally, darkened toward apex, with apical cap blackish (in alcohol, femur appears yellowish except apical dark cap); tibia dark brown to black with base yellow and median portion somewhat paler; tarsus dark brown to black except basal $1 / 3$ of 2 nd segment yellowish-white; basitarsus enlarged, spindle-shaped, 4.8 times as long as its greatest width, and 0.9 times as wide as greatest width of hind tibia which is as wide as hind femur; calcipala well developed, nearly as long as wide, and pedisulcus well developed. All femora sparsely or moderately covered with golden-yellow hairs on outer surface. Fore tibia densely covered with golden-yellow hairs on outer surface of basal $2 / 3$ of shaft; mid and hind tibiae also densely covered with golden-yellow hairs on posterior and outer surfaces of basal 1/2 of shaft. Wing. As in female except subbasal patch of white hairs on costa present only near juncture to humeral cross vein, and subcosta bare; length $2.8 \mathrm{~mm}$. Abdomen. Basal scale black, with fringe of yellow long hairs. Dorsal surfaces of abdominal segments entire- ly black, not shiny except segment 2 silvery shiny narrowly along anterior margin when illuminated; moderately covered with brown to black simple hairs; ventral surfaces of segments 2-4 yellowish-white though sternites of segments 3 and 4 light to medium brown; ventral surfaces of segments 5-8 dark brown to brownish-black. Genitalia. Coxite in ventral view (Fig. 2E) rectangular, 1.9-2.0 times as long as wide. Style in ventral view (Fig. 2E) short, 0.7 times as long as coxite, bent inwardly, nearly parallel-sided, with stout spine apically; style in ventrolateral view (Fig. 2G) broad, nearly parallel-sided from base to a little beyond middle, then abruptly tapered apically; style in end view (Fig. 2F) tapered inwards. Ventral plate in ventral view (Fig. 2H) lamellate, much shorter than wide, well sclerotized, with 3 concavities on posterior margin, and moderately covered with fine short setae on ventral surface except lateral portions bare; arm (Fig. $2 \mathrm{H}, \mathrm{J}$ ) of moderate length, slender, directed anteriorly, straight or curved inwardly; ventral plate in end view (Fig. 2I) with fine short setae centrally on posterior surface. Parameres (Fig. 2K) with 5 or 6 hooks of different sizes (6 or 7 hooks in Bentinck, 1955). Median sclerite (Fig. 2L) simple, club-shaped, narrow, widened near apex. Aedeagal membrane (Fig. 2K) moderately covered with spinous microsetae; dorsal plate (Fig. 2M) thin, with medial portion protruding posteriorly, appearing T-shaped. Ventral surface of 10th segment without any hairs near each posterolateral corner. Cercus (Fig. 2N, O) small, rounded and encircled by 10-12 simple hairs.

Pupa. Body length $3.2-3.5 \mathrm{~mm}$. Head. Integument (Fig. 3A) medium brown, moderately covered with round tubercles; antennal sheaths bare; frons with 2 short slender simple trichomes (Fig. 3A) on each side; face with 1 long somewhat stout simple or rarely bifid trichome (Fig. 3A) (2.6-2.8 times as long as frontal trichomes) on each side. Thorax. Integument medium brown, moderately covered with round tubercles, with 3 long slender simple trichomes with coiled apex mediodorsally, 2 slender simple trichomes (1 long and 1 medium-long) mediolaterally, 1 medium-long slender simple trichome posterolaterally, and 3 short slender simple trichomes ventrolaterally, on each side. Gill (Fig. 3B, C) with 6 long thread-like slender filaments arranged in pairs, all arising from short common basal stalk; 


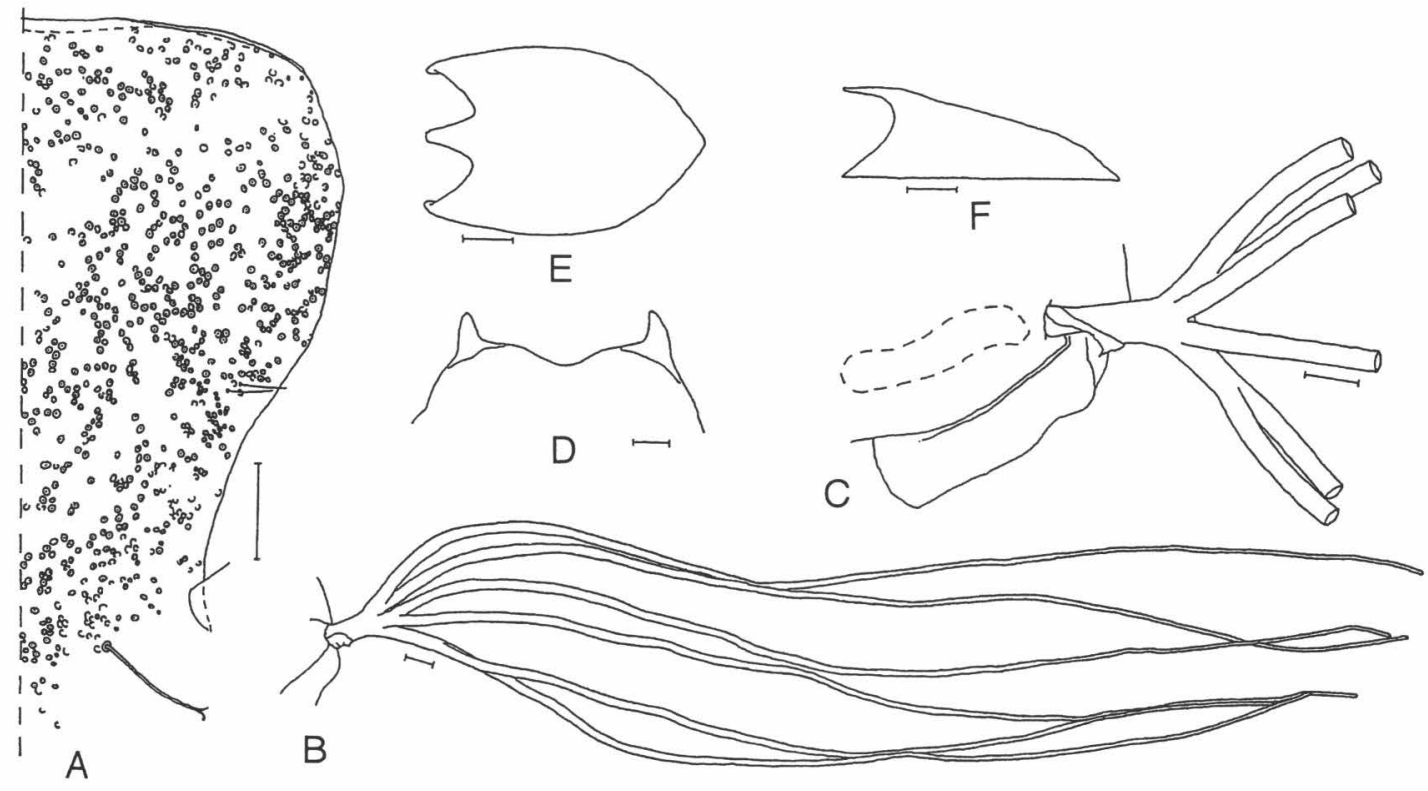

Fig. 3. Pupa of Simulium (Nevermannia) sasai. A, integument of frons; B, gill filaments (right side; outer view); C, basal portion of gill filaments (right side; outer view); D, terminal hooks (end view); E and F, cocoons (E, dorsal view; F, lateral view). Scale bars. $1.0 \mathrm{~mm}$ for E and F; $0.1 \mathrm{~mm}$ for A-C; $0.02 \mathrm{~mm}$ for D.

dorsal pair of filaments with short stalk, middle pair sessile or with short stalk, and ventral pair with medium-long stalk; all filaments tapered towards tip, extending anteriorly close together, subequal in length to one another (length variable from $3.0 \mathrm{~mm}$ to $3.7 \mathrm{~mm}$ depending upon individual pupae); cuticular surface with distinct annular ridges and furrows, and densely covered with minute tubercles of different sizes (larger ones on ridges and smaller ones on interridges). Abdomen. Dorsally, all segments densely and elaborately covered with minute tubercles; segments 1 and 2 medium brown; segment 1 with 1 mediumlong and 3 short slender simple setae on each side; segment 2 with 1 medium-long slender simple seta and 5 short spinous setae on each side; segments 3 and 4 each with 4 hooks and 1 very short spinous seta on each side; segment 5 bare; segments 6-8 each with spine-combs directed backward in transverse row and comb-like groups of minute spines on each side; segment 9 with a pair of distinct hornshaped terminal hooks curved posteroinwardly (Fig. 3D) as well as comb-like groups of minute spines. Ventrally, segments $3-8$ with comb-like groups of minute spines; segment 4 nearly transparent, with 1 simple or bifid hook (subequal in size to those on segments $5^{-7}$ ) and a few short simple slender setae on each side; segment 5 with a pair of bifid hooks submedially and a few short slender setae on each side; segments 6 and 7 each with 1 bifid or trifid hook submedially and 1 simple hook laterally and a few slender setae on each side. Cocoon (Fig. 3E, F). Simple, wall-pocket-shaped, compactly woven without open spaces in web, thin, with anterior margin thickly woven having a short anterodorsal projection, and extending ventrolaterally; individual threads visible; $4.2-5.7 \mathrm{~mm}$ long by $1.2-3.5 \mathrm{~mm}$ wide.

Mature larva. Body length 6.5-7.3 mm. Body (Fig. 4A) creamy white, with distinct reddishbrown markings on abdomen; i.e., segment 2 with 2 dorsal and 2 lateral spots, segments 3 and 4 each with 4 dorsal and 2 lateral spots; segment 5 with 2 dorsal spots anteriorly and a wide transverse dorsal band (though disconnected medially) posteriorly, segments 6 and 7 with colored area dorsolaterally (though becoming lighter posteriorly) on each side. Cephalic apotome (Fig. 4B) yellowish-white to yellow with posterior margin somewhat darkened; head spots medium to dark brown, well defined. Lateral surface of head capsule (Fig. $4 \mathrm{C})$ yellow, except eye-spot region white; eyebrow dark brown; all spots posterior to and below eye-spot region clearly positive. Ventral 

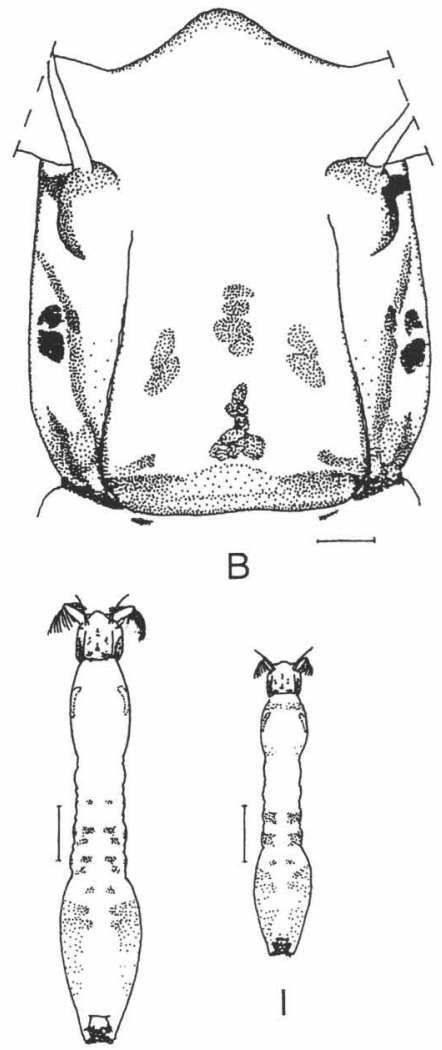

A
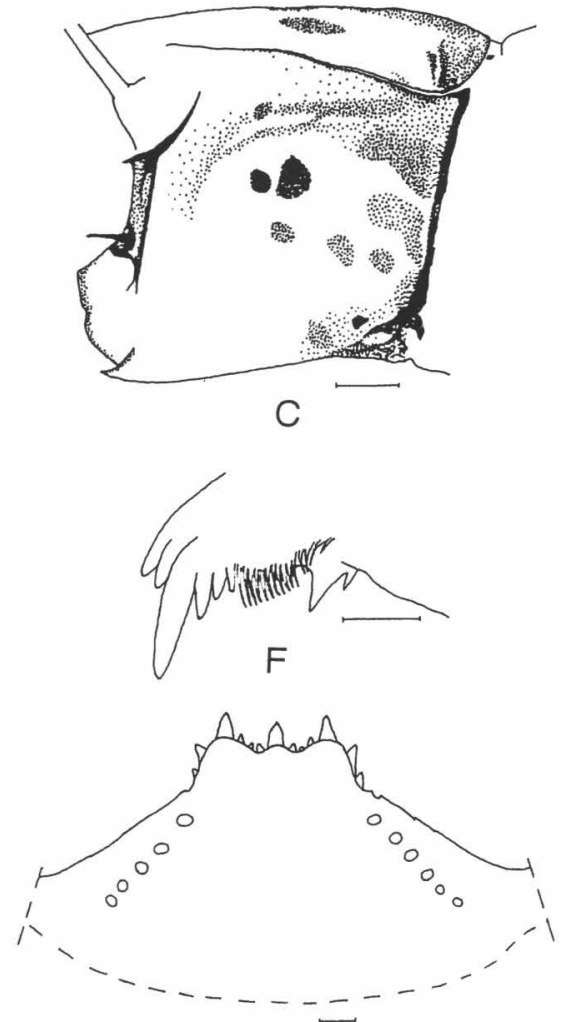

G
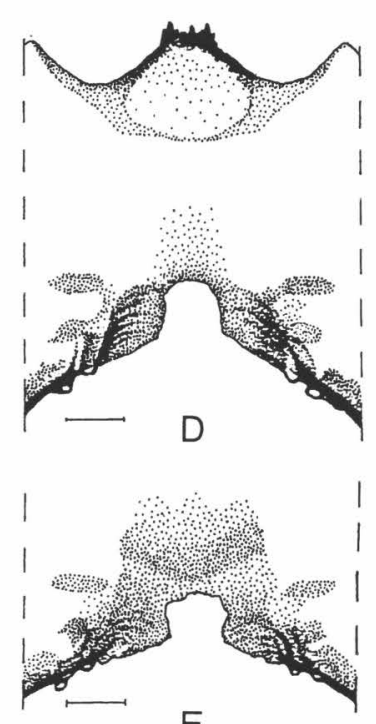

E

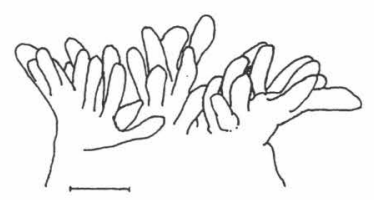

$\mathrm{H}$

Fig. 4. Mature larva of Simulium (Nevermannia) sasai. A, whole body (dorsal view); B-D, head capsules (B, dorsal view; C, lateral view; D, ventral view); E, postgenal cleft; F, mandible; G, hypostomium; H, rectal organ with finger-like secondary lobules; I, whole body of $S$. ( $N$.) mie showing different pattern of reddish-brown markings (dorsal view). Scale bars. $1.0 \mathrm{~mm}$ for A and I; $0.1 \mathrm{~mm}$ for B-E and $\mathrm{H} ; 0.02$ $\mathrm{mm}$ for $\mathrm{F}$ and $\mathrm{G}$.

surface of head capsule (Fig. 4D) yellow except lower portion of postgenal bridge near postgenal cleft darkened, and basal area on each side of postgenal cleft dark brown; horizontal and round spots on each side of postgenal cleft distinctively positive. Cervical sclerite (Fig. 4B) composed of 2 small elliptical pieces, not fused to occiput, widely separated medially from each other. Antenna consisting of $3 \mathrm{seg}$ ments and apical sensillum, much longer than stem of labral fan; proportional lengths of 1st, 2nd, and 3rd segments $1.0: 1.1: 0.8$. Labral fan with about 27 main rays. Mandible (Fig. 4F) with mandibular serrations consisting of 2 teeth (1 large and 1 small); large tooth making nearly a right angle with mandible on apical side; comb-teeth composed of 3 teeth, shortened from 1st to 3rd; supernumerary serrations absent. Hypostomium (Fig. 4G) with 9 apical teeth in row; median and corner teeth well developed; median tooth of 3 intermediate teeth on each side smallest; lateral serrations not or very weakly developed apically; 5-7 hypostomal bristles lying slightly divergent posteriorly from lateral margin on each side. Postgenal cleft (Fig. 4D, E) small, 0.3-0.4 times as long as postgenal bridge, with anterior margin somewhat variable in shape, usually arched or simple straight but sometimes sinuous. Thoracic cuticle bare. Abdominal cuticle bare except both sides of anal sclerite moderately covered with simple colorless setae. Rectal scales present. Rectal organ (Fig. 4H) compound, each of 3 lobes with 5-10 finger-like secondary lobules. Anal sclerite of usual $\mathrm{X}$-form, with anterior arms 0.9 times as long as posterior ones, broadly sclerotized at base; accessory sclerite absent. Last abdominal seg- 
ment much expanded ventally forming large ventral papilla. Posterior circlet with $86-100$ rows of up to 12 or 13 hooklets per row.

SPECIMENS EXAMINED. One female and one male reared from pupae, 3 pupae, 7 mature larvae, at Sengokuhara, Hakone, Ashigarashimo, Kanagawa Prefecture, Japan, 17.X.1999, by K. Saito.

BIOLOGICAL NOTES. The pupae and larvae of $S$. (N.) sasai were found on the surfaces of leaves of trailing grasses and fallen leaves in a slow-flowing small stream (water temperature $13.0^{\circ} \mathrm{C}$ ). Associated species were $S$. (N.) mie Ogata and Sasa, and $S$. (N.) uchidai (Takahasi).
DISTRIBUTION. Japan (Ishikawa, Nagano, Tochigi, Kanagawa, Tottori, Oita, Kagoshima).

REMARKS. The larval stage of $S$. $(N$.) sasai, described here for the first time, clearly shows its morphological characters typical of the feuerborni species-group proposed by Datta (1973) and redefined by Takaoka (2003): i.e., postgenal cleft small, mandible without supernumerary serrations, and abdomen with colored markings. The pattern of the last character (Fig. 4A) is species-specific, thus being used at the larval stage to distinguish $S$. (N.) sasai from its related species in Japan, viz., S. (N.) mie, S. (N.) morisonoi Takaoka and $S$. (N.) saitoi Takaoka. The pattern of

Table 1. Differences in several morphological features among four species of the feuerborni speciesgroup in Japan.

\begin{tabular}{|c|c|c|c|c|}
\hline \multirow{2}{*}{ Features } & \multicolumn{4}{|c|}{ Species } \\
\hline & mie & morisonoi & saitoi & sasai \\
\hline \multicolumn{5}{|l|}{ Female } \\
\hline Outer margin of mandible & Smooth & Smooth & Serrate & Smooth \\
\hline Color of scutum & $\begin{array}{c}\text { Chocolate-brown to } \\
\text { brownish-black }\end{array}$ & Chocolate-brown & Orange-yellow & Brownish-black \\
\hline Vittae of scutum & Present & Present & Present & Absent \\
\hline $\begin{array}{l}\text { Anterior projection of } \\
\text { genital fork }\end{array}$ & Medium to large & Small & Medium & Large \\
\hline \multicolumn{5}{|l|}{ Male } \\
\hline $\begin{array}{l}\text { No. of horizontal rows of } \\
\text { large eye facets }\end{array}$ & 14 & 14 & 17 & 22 \\
\hline Color of scutum & Black & Chocolate-brown & Orange-yellow & Black \\
\hline No. of parameral hooks & $7-9$ & 7 & 9 & $5-7$ \\
\hline \multicolumn{5}{|l|}{ Pupa } \\
\hline $\begin{array}{l}\text { Tubercles on head } \\
\text { integument }\end{array}$ & Dense & Dense & Moderate & Moderate \\
\hline $\begin{array}{l}\text { Anterodorsal projection of } \\
\text { cocoon }\end{array}$ & Absent & Absent & Absent & Present \\
\hline \multicolumn{5}{|l|}{ Larva } \\
\hline Colored band on thorax & Present & Present & Absent & Absent \\
\hline $\begin{array}{l}\text { Colored markings on } \\
\text { abdomen }\end{array}$ & Present & Present & Absent & Present \\
\hline No. main rays of labral fan & $30-34$ & $22-26$ & ca. 36 & ca. 27 \\
\hline \multicolumn{5}{|l|}{$\begin{array}{l}\text { Secondary lobules of rectal } \\
\text { organ }\end{array}$} \\
\hline Shape & Finger-like & Thumb-like & Finger-like & Finger-like \\
\hline No. per lobe & $8-13$ & $3-5$ & $9-11$ & $5-10$ \\
\hline
\end{tabular}

Morphological characters for first three species were cited from Bentinck $(1955)$, Takaoka $(1973,1976)$ and Takaoka and Saito (2000). 
colored markings on the larval body of $S$. (N.) mie is shown in Fig. 4I, which is almost the same as that of $S$. (N.) morisonoi (Takaoka, 1973, 1976), and S. (N.) saitoi lacks such color markings (as a single exception among species of this speciesgroup) (Takaoka and Saito, 2000).

Several other morphological features differing between this species and these three related species are shown in Table 1. It makes it easier to distinguish $S$. ( $N$.) sasai even at the adult stage than before. The key characters of $S$. (N.) sasai are brownish-black scutum without 3 longitudinal vittae in the female and large upper eye facets in 22 horizontal rows in the male, respectively.

Among the 12 other known species of the feuerborni species-group (Crosskey and Howards, 1997; Takaoka, 2003), only three species, i.e., S. (N.) feuerborni Edwards from Indonesia, Peninsular Malaysia and Thailand, S. (N.) leigongshanense Chen and Zhang from China, and $S$. ( $N$.) praelargum Datta from India, have the cocoon with a distinct anterodorsal projection like $S$. (N.) sasai. However, S. (N.) sasai differs from these species in the female by the brownish-black scutum without longitudinal vittae and in the pupae by the arrangement of the gill filaments. Five other species of the same species-group have the simple cocoon and the different arrangement of the gill filaments, thus differing from $S$. (N.) sasai.

The remaining four known species of the feuerborni species-group were described from adult males (and also females in one species) alone, and then, their pupal and larval stages have remained unknown. Among these, S. (N.) fuscinervis recorded from Sabah (Edwards, 1933) differs from $S$. (N.) sasai by having the paramere with 10 or 11 hooks; $S$. (N.) bryopodium, described from Palawan Island, Philippines (Delfinado, 1971), also differs by the brown scutum; $S$. (N.) senile, described from West Himalaya (Brunetti, 1911), is different by the style with no apical spine; S. (N.) rufithorax, described from a male and four females collected from India (Brunetti, 1911), has a reddishbrown scutum according to the original description.

\section{REFERENCES}

Bentinck, W. 1955. The Black Flies of Japan and Korea (Diptera: Simuliidae). 23 pp., 406 Medical General Laboratory U.S. Army, Tokyo.

Brunetti, E. 1911. New Oriental Nematocera. Rec. Indian Mus., 4: 259-316.

Crosskey, R. W. and Howard, T. M. 1997. A New Taxonomic and Geographical Inventory of World Blackflies (Diptera: Simuliidae). 144 pp., The Natural History Museum, London.

Datta, M. 1973. New species of black flies (Diptera: Simuliidae) of the subgenera Eusimulium Roubaud and Gomphostilbia Enderlein from Darjeeling area, India. Orient. Insects, 7: 363-402.

Delfinado, M. D. 1971. Some Simuliidae and Curtonotidae from the Philippines and the Bismarck Islands (Insecta, Diptera). Steenstrupia, 1: 131-139.

Edwards, F. W. 1933. Diptera Nematocera from Mount Kinabalu. J. Fed. Malay States Mus., 17: 223-296.

Takaoka, H. 1973. Descriptions of 2 new species of blackflies, Simulium (Gomphostilbia) tokarense and S. (Eusimulium) morisonoi (Diptera: Simuliidae), from the Tokara Islands, Japan. Jpn. J. Sanit. Zool., 23: 201-207.

Takaoka, H. 1976. Studies on black flies of the Nansei Islands, Japan (Simuliidae; Diptera). I. On six species of the subgenus Eusimulium Roubaud, with the descriptions of Simulium (E.) satsumense sp. nov. and $S$. (E.) subcostatum koshikiense ssp. nov. Jpn. J. Sanit. Zool., 27: 163-180.

Takaoka, H. 2003. The Black Flies (Diptera: Simuliidae) of Sulawesi, Maluku and Irian Jaya. xxii+581 pp., Kyushu University Press, Fukuoka.

Takaoka, H., Ochoa, J. O. and Yamamoto, S. 1977. Notes on the fauna and distribution of black-flies in Kyushu, Japan (Simuliidae; Diptera). Jpn. J. Sanit. Zool., 28: 341-347 (In Japanese with English summary).

Takaoka, H. and Saito, K. 2000. Description of a new species of Simulium (Nevermannia) from Japan (Diptera: Simuliidae). Jpn. J. Trop. Med. Hyg., 28: 19-24. 